\title{
Random Amplified Polymorphic DNA in Perennial Ryegrass: A Comparison of Bulk Samples vs. Individuals
}

\author{
Patricia M. Sweeney and T. Karl Danneberger \\ Department of Agronomy, Ohio State University, Columbus, OH 43210
}

Additional index words. DNA Amplification Fingerprinting (DAF), Arbitrarily Primed Polymerase Chain Reaction (AP-PCR), Amplification Fragment Length Polymorphisms (AFLP)

\begin{abstract}
The usefulness of random amplified polymorphic DNA (RAPD) in characterizing two perennial ryegrass (Lolium perenne L.) synthetic cultivars, 'Accolade' and 'Caravelle', was tested. Two out of $\mathbf{1 0}$ arbitrary primers produced three RAPD markers that distinguished bulk samples of 30 seedlings. Additional fragments were apparent when DNA from individual seedlings was amplified. Amplification products from bulk samples were not simply the sum of amplification products of individual seedlings and did not reflect all the diversity within or between the cultivars. The study illustrates the need to screen individuals to accurately evaluate the genotypic composition of a synthetic cultivar or heterogeneous population.
\end{abstract}

Williams et al. (1990), Welsh and McClelland (1990), and Caetano-Anolles et al. (199 lb) have demonstrated the use of single arbitrary primers to amplify DNA. The amplification is similar to the polymerase chain reaction (PCR) and generates an almost infinite number of polymorphisms useful in cultivar identification (Caetano-Anolles et al., 199 la), in production of genetic markers (Martin et al., 1991), and in the study of evolution (Arnold et al., 1991) and population genetics (Chalmers et al., 1992).

Species that are vegetatively propagated and ones that are easily self-pollinated were used in the previous studies involving improved plant species. Presumably, the entities used for amplification were vegetative clones, inbred lines, or hybrids and hence were homogeneous. Because the results of amplification of a single individual from a homogeneous population are expected to be identical to that of a pooled sample of the identical individuals, relationships between bulk and individual samples have not been addressed for these species. Perennial ryegrass synthetic cultivars result from the interpollination of at least four parental plants (Wilkins, 199 1). Because perennial ryegrass is a highly self-incompatible, outcrossing species, the parents are heterozy gous. The interpollination of these heterozy gous parents virtually ensures that perennial ryegrass synthetic cultivars are heterogeneous populations consisting of genetically unique individuals.

Received for publication 6 July 1993, Accepted for publication 1 Dec. 1993, Salaries and research supportwereprovidedbystate and federal funds appropriated to the Ohio Agricultural Research and DevelopmentCenter,OhioStateUniv.Additional support was provided by the Ohio Turfgrass Foundation.The cost of publishing this paper was defrayed inpartbythe payment of page charges.Under postal regulations, this paper therefore must be hereby marked advertisement solely to indicate this fact.
Although specific mechanisms involved in amplification using single arbitrary primers have not been characterized, there probably is competition among DNA sequences for the substrates in the reaction. In PCR, DNA with greater homology to the primer maybe amplified at the expense of other DNA (Gibbs et al., 1989), and some DNA may be preferentially amplified under specific conditions (Kirkpatrick et al., 1991), Michelmore et al. (199 1) determined that rare alleles were not detected when they comprised $<4 \%$ of the PCR mixture. These phenomena could also occur when arbitrary primers are used. As a result, the amplification of a genetically mixed sample of many individuals (bulk sample) may not produce the same fragments that would be generated by the individuals in the mixture.

Comparing random amplified polymorphic DNA (RAPD) markers from assays of bulk samples may be adequate for identifying cultivars in some instances, but may not accurately reflect the diversity among or within cultivars. Assaying individuals within a heterogeneous population may be useful in identifying closely related populations and in studying population diversity, evolutionary relationships, the behavior of cultivars in mixtures, and response to selection pressure.

Screening individual plants in sample populations requires a procedure that is quick and simple. Although amplification and visualization of RAPD requires few steps and inexpensive equipment, DNA extraction using conventional methods is time-consuming and labor-intensive. Edwards et al. (1991) reported a simple rapid procedure to prepare plant DNA for PCR. The procedure has two steps, requires only a table-top centrifuge, and has been successfully used to prepare fine fescue (Festuca longifolia Thuill., F. rubra L. ssp. rubra, F. rubra L. ssp. commutata Gaud.) DNA for amplification using arbitrary primers (Sweeney et al., 1993). Perennial ryegrass
DNA extracted in this way could be used to generate RADP markers.

The objectives of this study were to determine the fidelity of amplification products using DNA extracted as described by Edwards et al. (1991) and arbitrary primers, to determine the number of RADP markers produced using 10 arbitrary primers, and to evaluate differences between bulk samples of a cultivar and multiple individual seedlings from the same cultivar.

\section{Materials and Methods}

DNA was extracted from 7-to 20-day-old seedlings of 'Accolade' and 'Caravelle' perennial ryegrass ( 0 . M. Scott and Sons, Marysville, Ohio). Seed was germinated at $26 \mathrm{C}$ on blotter paper in a lighted growth chamber. The protocol described by Edwards et al. (1991) was followed for DNA extraction of individual seedlings. Tissue was placed in a $1.5-\mathrm{ml}$ microfuge tube and macerated with the tip of a pasteur pipet dipped in extraction buffer [200 mm Tris-HCl (pH 7.5), $290 \mathrm{~mm}$ $\mathrm{NaCl}, 25$ mм EDTA, $0.5 \%$ sodium dodecyl sulfate]. The macerated samples were kept on ice until all samples had been prepared (usually $<1 \mathrm{~h}$ ). The rest of the extraction was performed at room temperature. Extraction buffer $(400 \mathrm{Ll})$ was added to the samples. An extraction control consisting of the extraction buffer without DNA was included. Samples were vortexed $5 \mathrm{see}$, then centrifuged $2 \mathrm{~min}$ at $15,600 \times g$. The supernatant $(300 \mu l)$ was transferred to a clean microfuge tube, and $300 \mu \mathrm{l}$ $100 \%$ isopropanol was added. Tubes were inverted to mix the reagents, righted, and allowed to stand for $2 \mathrm{~min}$. After centrifuging the samples again for $7 \mathrm{~min}$ at $15,600 \times g$, the supernatant was discarded and the remaining pellet dried 15 min under vacuum. The dried pellet was then suspended in $50 \mu 1$ Tris EDTA (TE) $[10$ mм Tris- $\mathrm{HCl}$ (pH 7.5), 1 mm EDTA] and stored at $-20 \mathrm{C}$. Volumes were increased 5-fold for extraction of the bulk samples. DNA concentrations in the samples were estimated using a TKO 100 Mini Fluorometer (Hoefer Scientific Instruments, San Francisco). Control extractions contained no detectable DNA. DNA samples were diluted with TE to 2 to 5 $\mu \mathrm{g} \mathrm{DNA} / \mathrm{ml}$ for use in the amplification.

Three extractions of leaf tissue $(\approx 2 \mathrm{~cm})$ from a single plant of each cultivar were made to test the fidelity of the extraction and amplification. Bulk extractions consisted of pooling $1 \mathrm{~cm}$ leaf tissue from each of 30 seedlings. Two bulk extractions from three different seed lots of each cultivar were compared. DNA from leaf tissue of a single blade $(\approx 6 \mathrm{~cm})$ from each of five individual seedlings of each cultivar was extracted for comparison to bulk samples of the cultivars.

A protocol similar to the RAPD technique described by Williams et al. (1991) was used to amplify DNA. Ten primers (201 to 210) from a set of 100 decamers supplied by J.E. Carlson, Univ. of British Columbia, were screened. In lieu of a hot start, DNA samples were placed in a boiling-water bath for $5 \mathrm{~min}$ before adding the polymerase. After denatur- 
ing, samples were immediately cooled in ice for $3 \mathrm{~min}$ to prevent annealing of DNA. The 25- $\mu$ l amplification reaction mixture contained $10 \mathrm{~mm}$ Tris- $\mathrm{HCl}$ (pH 8.3); $50 \mathrm{~mm} \mathrm{KC1;} 2 \mathrm{~mm}$ $\mathrm{MgCl}_{2} ; 0.001 \%$ gelatin; $0.2 \mu \mathrm{M}$ primer; $0.1 \mathrm{~mm}$ each dATP, dGTP, dCTP, and dTTP; 4 to 5 units of DNA polymerase from Thermus aquaticus (Taq DNA Polymerase; GIBCO BRL, Grand Island, N.Y.); and 2 to 5 ng DNA template. Before the DNA was added, reagents were combined then divided into individual aliquots for each reaction. A reaction containing $1 \mu$ lof the DNA extraction control was included in each experiment. Amplification was performed in a Microcycler (Eppendorf, Fremont, Calif.) programmed for 35 or 40 cycles of $30 \mathrm{sec}$ at $94 \mathrm{C}, 1 \mathrm{~min}$ at 39C, and $1 \mathrm{~min}$ at $72 \mathrm{C}$. For each primer, bulk samples of the two cultivars were used in at least two separate amplifications. Amplifications using extractions from individual seedlings were repeated for primers 202 and 209.

Gels containing $2 \%$ agarose, $0.5 \mathrm{mg}$ ethidium bromide/liter, and TBE [89 mM Tris-borate, $89 \mathrm{~mm}$ boric acid, and $2 \mathrm{~mm}$ EDTA] were used to separate amplification products. Eight microliters of each reaction was mixed with $2 \mu \mathrm{l}$ sample buffer III [0.25\% bromophenol blue, $0.25 \%$ xylene cyanol, $30 \%$ glycerol (Sambrook et al., 1989)] for the assay. Amplified DNA fragments were detected and photographed using ultraviolet light.

\section{Results and Discussion}

The number of amplification products for each primer ranged from $\mathrm{O}$ to 10 (Table 1). Two primers, 202 and 209, revealed three RADP markers that distinguished bulk samples of the cultivars. Twelve additional RADP markers were observed when individuals were compared (Table 1). These additional polymorphisms could be useful in studies of population genetics or in the identification of closely related populations. However, because comparing bulk samples is easier than evaluating many individuals, bulk assays may be preferable for characterizing populations if consistent polymorphisms between the bulk samples can be obtained. Our results indicate that relatively few primers need to be screened to find ones useful for characterizing populations.

Amplification of DNA from individual seedlings of a cultivar produced fragments similar to those produced by amplification of DNA from bulk samples of the cultivar, but

Table 1. Number of amplification products of bulk extractions ( 30 individuals) and individual extractions (10) of two perennial ryegrass cultivars using 10 arbitrary primers.

\begin{tabular}{|c|c|c|c|c|c|}
\hline \multirow[b]{2}{*}{ Primer } & \multirow[b]{2}{*}{ Sequence } & \multicolumn{2}{|c|}{ Bulk extractions } & \multicolumn{2}{|c|}{ Individual extractions } \\
\hline & & Bands & $\overline{\text { RAPD }}$ & Bands & $\overline{\text { RAPD }}$ \\
\hline$\overline{201}$ & CTGGGGATTT & 0 & -- & --- & --- \\
\hline 202 & GAGCACTTAC & 6 & 1 & 9 & 4 \\
\hline 203 & CACGGCGAGT & 6 & 0 & 6 & 0 \\
\hline 204 & TTCGGGCCGT & 2 & 0 & 4 & 1 \\
\hline 205 & CGGTTTGGAA & 3 & 0 & 3 & 1 \\
\hline 206 & GAGGACGTCC & 3 & 0 & 3 & 1 \\
\hline 207 & CATATCAGGC & 0 & -- & --- & --- \\
\hline 208 & ACGGCCGACC & 5 & 0 & 5 & 0 \\
\hline 209 & TGCACTGGAG & 6 & 2 & 10 & 7 \\
\hline 210 & GCACCGAGAG & 3 & 0 & 4 & 1 \\
\hline
\end{tabular}

only two primers (203 and 208) produced single seedling banding patterns identical to the bulk banding patterns. The other primers produced additional bands (relative to the fragments produced when bulk DNA was used) when single seedlings were assayed. Figure 1 shows amplification patterns using primer 202 and extracts from single seedlings and from bulks of 30 seedlings and is representative of the different amplification patterns seen in the bulk vs. single seedlings. A 730-base pair (bp) fragment that distinguished 'Accolade' from 'Caravelle' in the bulk samples was not evident in every individual of 'Accolade'. RADP markers at 500 and $910 \mathrm{bp}$ that were not evident in the bulk assays were observed within the cultivars (Fig. 1). Our results agree with those of Michelmore et al. (1991) and indicate that rarer alleles may not be detected when several genotypes are pooled for amplification.

- Interestingly, even though the two cultivars in the study came from diverse backgrounds ('Accolade' was derived from germplasm originating in the eastern United States and 'Caravelle' from seed collected in the wild in France), results of the individual plant assays suggest that many of the same polymorphisms were expressed in both cultivars. Eleven of the 16 polymorphic fragments were shared by the two cultivars. Only one fragment was present in every individual from one cultivar but absent in every individual in the other cultivar. The cultivars shared 40 of the 44 amplified fragments. These results suggest that there is more diversity within the perennial ryegrass cultivars than between them.

Amplification using bulk DNA extractions from three seed lots of each cultivar as template DNA gave consistent results using primer 209 (Fig. 2). The same major bands were observed in the amplification products of the
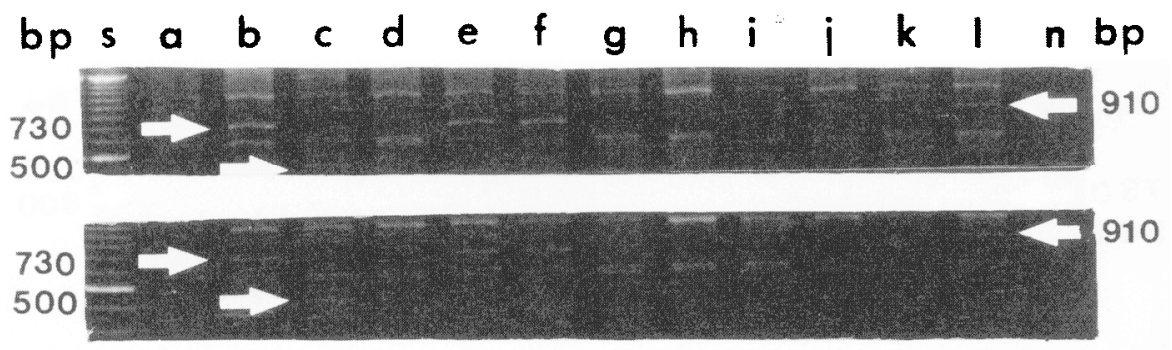

Fig. 1. Agarose gel electrophoresis of products from two separate amplifications using primer 202 and DNA extracts from 'Accolade' (lanes a-e: single seedlings; f: bulk sample) and 'Caravelle' (lanes h-l: single seedlings; $\mathrm{g}$ : bulk sample) perennial ryegrass ( $\mathrm{s}=$ size marker, $\mathrm{n}=$ control).

six separate extracts of each cultivar. In addition to the fragments that are apparent in the amplification products of both cultivars (930 and $800 \mathrm{bp}$ ), several fragments appear to be polymorphic. A 730-bp fragment present in the amplification product of the bulk 'Accolade' extracts is absent in the amplification products of 'Caravelle'. A 540-bp fragment, which was present in the amplification products of bulk 'Accolade' extractions, was not visible in the amplification products of bulk extracts-of 'Caravelle'.

The three extractions from individual seedlings produced identical fragments within an amplification run using primer 209 and demonstrated the fidelity of the extraction and amplification procedures. The three extractions from an individual of 'Accolade' consistently produced 540-, 730-, 800-, 1040-, 1130-, $1300-$, and $1500-\mathrm{bp}$ fragments. The three extractions from an individual of 'Caravelle' amplification products included 800- and 1040bp fragments; however, the 1300- and 1500bp fragments were barely detectable, and the 540-, 730-, and 1130-bp fragments were not visible. The major fragments produced using individual seedling. DNA as template and primer 202 were also identical in separate amplifications. Figure 1 shows two separate amplifications of the same extractions of 'Accolade' and 'Caravelle'. Major amplification products for each extraction are identical in the two runs. In each amplification, extracts "b" and "e" exhibit 730-bp fragments that were not visible in the amplification products of the other individual seedling extractions. This fragment appears to be unique to 'Accolade'. A 500-bp fragment is seen only in the products of extract "c," and a 910-bp fragment is only visible in "l."

The extraction protocol yielded DNA that was consistently amplified regardless of whether bulk samples of 30 seedlings or individual seedlings were assayed. Useful RADP markers were detected between bulk samples of the two cultivars when 10 primers were screened. These polymorphisms were easy to find and suggest that RAPD could be used in cultivar identification. The amplification patterns of individual seedlings of a cultivar were not necessarily identical to the amplification patterns of a bulk sample. Polymorphisms detected between the bulk samples of the two cultivars were often present within the cultivars. These fragments were consistently amplified for a given individual seedling for the two primers we tested. We suggest that assay- 
A

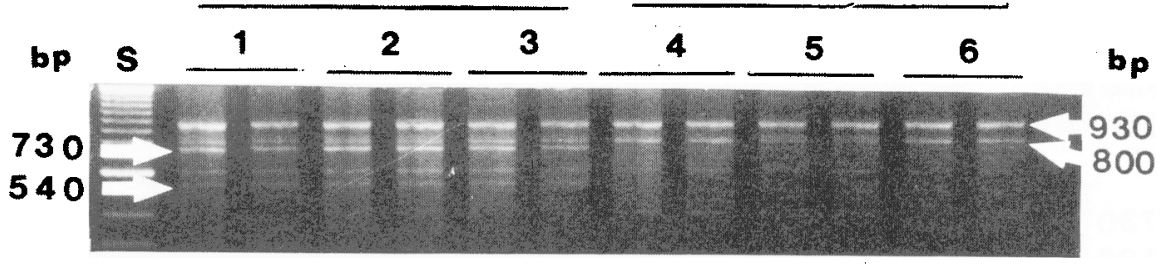

Fig. 2. Agarose gel electrophoresis of amplification products using primer 209 and bulk DNA extracts from three seed lots (1-3) of 'Accolade' (lanes 1-6) and three seed lots (4-6) of 'Caravelle' (lanes 7-12) perennial ryegrass $(\mathrm{s}=$ size marker, $\mathrm{n}=$ control).

ing individuals from a population may be useful in genotypic characterization of blends, and for diversity, pedigree, or competition studies.

\section{Literature Cited}

Arnold, M.L., C.M. Buckner, and J.J. Robinson. 1991.Pollen-mediatedintrogressionandhybrid speciationinLouisiana irises. Proc. Natl. Acad. Sci.88:1398-1402.

Caetano-Anolles, G., B.J. Bassam, and P.M. Gresshoff. 1991a. DNA amplification fingerprinting: A strategy for genome analysis. Plant Mol.Biol.Rptr.9:294-307.

Caetano-Anolles, G., B.J. Bassam, and P.M. Gresshoff. 1991b. DNA amplification finger- printing using very short arbitrary oligonucleotide primers. Biotechnology 9:553-557. andW.Powell.1992.Detectionof genetic variaion between and within populations of Gliricidia spepium andG. maculata using RAPD markers. Heredity 69:465-472.

Edwards,K.,C. Johnstone, and C. Thompson. 1991. Asimpleandrapid method forthe preparation of plant genomic DNA for PCR analysis. Nucleic Acids Res. 19:1349.

Gibbs, R.A., P. Nguyen, and C.T. Caskey. 1989. Detection of single DNA base differences by competitive oligonucleotide priming. Nucleic Acids Res. 17:2437-2448.

Kirkpatrick,B.W.,C.M. Cowan, and M.R. Dentine. 1991.Differential amplification of alleles: Po-
Chalmers,K.J., R. Waugh, J.I. Sprent, A.J. Simons, tential for misclassification with PCR genotyping. Animal Biotech. 2(1):1-14.

Martin, G. B., J.G.K. Williams, and S.D. Tanksley. 1991.Rapid identification of markers linked to Pseudomonas resistance gene in tomato by using random primers and near-isogenic lines. Proc. Natl. Acad. Sci. 88:2336-2340.

Michelmore,R.W.,I.Paran,andR.V. Kesseli. 1991. Identification of markers linked to diseaseresistance genes by bulked segregant analysis: A rapid method to detect markers in specific genomic regions by using segregating populations. Proc. Natl. Acad. Sci. 88:9828-9832.

Sambrook, J., E.F. Fritsch, and T. Maniatis. 1989. Molecular cloning: A laboratory manual. Cold Spring Harbor Lab. Press, Cold Spring Harbor, N.Y.

Sweeney, P.M., T.K. Danneberger, and J.K. Kamalay. 1993. Fidelity of amplification fragment length polymorphisms (AFLP's) within multiple extractions from single seedlings of hard, chewings and red fescue Proc. 7th Intl. Turfgrass Soc. Res. Conf. 7:768-774.

Welsh,J. and M. McClelland. 1990. Fingerprinting genomes using PCR with arbitrary primers. Nucleic Acids Res. 18:7213-7218.

Wilkins, P.W. 1991. Breeding perennial ryegrass foragriculture. Euphytica 52:201-214.

Williams, J. G. K., A.R. Kubelik, K.J. Livak, J.A. Rafalski, and S.V. Tingey. 1990. DNA polymorphisms amplified by arbitrary primers are useful as genetic markers. Nucleic Acids Res. 18:6531-6535. 